\title{
Comment on: Eucalcemic Parathyroid Hormone Elevation After Parathyroidectomy for Primary Sporadic Hyperparathyroidism: Risk Factors, Trend, and Outcome
}

\author{
P. V. Pradeep, MS, DNB, MRCS, FRCS, MCh and B. R. Srikanth, MD \\ Endocrine Surgery, Narayana Medical College, Nellore, AP, India
}

\section{TO THE EDITORS:}

We read the article "Eucalcemic parathyroid hormone elevation after parathyroidectomy for primary sporadic hyperparathyroidism: risk factors, trend, and outcome" by Lang et al. ${ }^{1}$ with interest. The authors have addressed a very valid and important scenario after parathyroidectomy. We made similar observations earlier in our patients. We also found that parathyroid hormone (PTH) levels and recovery of bones after surgery were influenced by vitamin D (Vit D) deficiency. ${ }^{2}$ We have certain comments and queries regarding this study.

Group B contained patients with high serum creatinine and lower Vit D levels. The total parathyroid tissue excised was also greater in this group. It is also noted that the 10-min intraoperative (IO)PTH was still not within the normal range in group B after parathyroidectomy. Have the authors reasonably ruled out secondary hyperparathyroidism/multiglandular disease in this group?

In group B, post operative PTH started to increase from the third month onwards, or maybe even earlier since PTH was not assayed at any other time point between 1 and 3 months after surgery. The authors do not mention whether
Vit D was persistently low during follow-up or whether serum creatinine was persistently high in group B. Persistently low Vit D could explain high PTH and normal calcium. It may also be possible that the authors are missing some recurrent disease masked due to associated Vit D deficiency. It Vit D correction were done, one could accurately predict how many of these cases in group B were recurrences. Within group B, at 12 months after surgery, 26 had normal PTH. Separate comparison of the preoperative characteristics of this group with the other members of group B could shed more light on the etiology.

\section{REFERENCES}

1. Hung-Hin Lang B, Yu-Hong Wong I, Pun Wong K, et al. Eucalcemic parathyroid hormone elevation after parathyroidectomy for primary sporadic hyperparathyroidism: risk factors, trend, and outcome. Ann Surg Oncol. 2011. http://www.springerlink. com/content/y $7 \times 2870721432526$

2. Pradeep PV, Mishra A, Agarwal G, Agarwal A, Verma AK, Mishra SK. Long-term outcome after parathyroidectomy in patients with advanced primary hyperparathyroidism and associated vitamin D deficiency. World J Surg. 2008;32(5):829-35
(C) Society of Surgical Oncology 2017

First Received: 20 October 2017;

Published Online: 30 October 2017

P. V. Pradeep, MS, DNB, MRCS, FRCS, MCh

e-mail: pradeepputhenveetil@yahoo.co.in 